NASA Technical Memorandum 106543

AIAA-94-0374

\title{
Low Earth Orbit Durability Evaluation of Protected Silicone for Advanced \\ Refractive Photovoltaic \\ Concentrator Arrays
}

Kim K. de Groh

Lewis Research Center

Cleveland, Ohio

and

Timothy A. McCollum

Cleveland State University

Cleveland, Ohio

Prepared for the

AIAA 32nd Aerospace Sciences Meeting and Exhibit

sponsored by the American Institute of Aeronautics and Astronautics

Reno, Nevada, January 10-13, 1994 


\title{
LOW EARTH ORBIT DURABILITY EVALUATION OF PROTECTED SILICONE FOR ADVANCED REFRACTIVE PHOTOVOLTAIC CONCENTRATOR ARRAYS
}

\author{
Kim K. de Groh \\ NASA Lewis Research Center \\ Cleveland, Ohio \\ Timothy A. McCollum \\ Cleveland State University \\ Cleveland, Ohio
}

\begin{abstract}
The need for efficient, cost effective sources of electrical power in space has led to the development of photovoltaic power systems which make use of novel refractive solar concentrators. These concentrators have been conceived in both point-focus and linear-focus designs. Current concentrator lenses are fabricated from flexible silicones with Fresnel facets along their inside surface. To insure the efficient operation of these power systems, the concentrator lenses must be durable and the silicone material must remain specularly transmitting over a reasonable lifetime in low Earth orbit (LEO) and other space environments. Because of the vulnerability of silicones to atomic oxygen and ultraviolet radiation in LEO these lenses have been coated with a multi-layer metal oxide protective coating. The objective of this research was to evaluate the LEO durability of the multilayer coated silicone for advanced refractive photovoltaic concentrator arrays with respect to optical properties and microstructure. Flat metal oxide coated silicone samples were exposed to ground-laboratory and in-space atomic oxygen for durability evaluation.
\end{abstract}

\section{Introduction}

Since 1986, NASA Lewis Research Center has been developing the mini-dome Fresnel lens photovoltaic concentrator, a novel, point-focus refractive concentrator space power system that offers a number of advantages (extremely high power density, relatively low weight, radiation hardness, potential for array cost reduction, etc.) over existing systems. ${ }^{1-3}$ The mini-dome Fresnel lens concentrator uses a unique optical design (a domed shape with individually tailored Fresnel facets on the inside surface) that is

Copyright ${ }^{\circ} 1994$ by the American Institute of Aeronautics and Astronautics, Inc. No copyright is asserted in the United States Under Title 17, U.S. Code. The U.S. Government has a royaltyfree license to exercise all rights under the copyright claimed herein for Governmental Purposes. All other rights are reserved by the copyright owner. very efficient and shape error tolerant. Figure 1 is a illustration of a single square edged mini-dome Fresnel lens. The general concept of the point-focus minidome concentrator has since been applied to a linearfocus design as well. The linear Fresnel lens concentrator has the same advantages as the point-focus design with the added advantage of requiring precise sun tracking only within a single axis. ${ }^{4}$ These advanced refractive concentrator designs, along with the introduction of new high efficiency photovoltaic devices could have a significant impact on future power systems for a wide range of missions (LEO, geosynchronous orbits (GEO), high radiation orbits, etc.). ${ }^{1-4}$

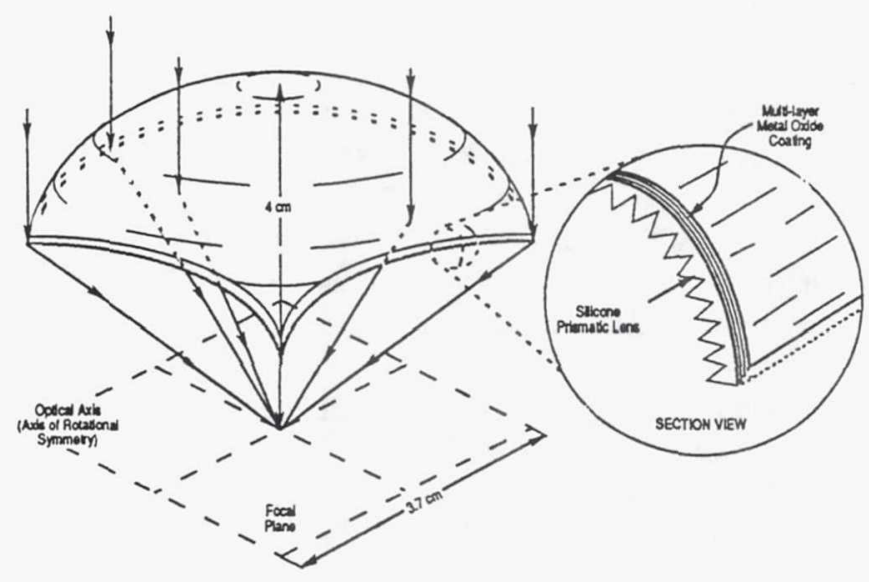

Figure 1. Mini-dome Fresnel lens photovoltaic concentrator.

Under the current advanced refractive concentrator program, the concentrator lens is made using a flexible silicone (either DC 93-500 silicone or RTV 615). Because silicones are known to react with atomic oxygen ${ }^{5}$, the predominant species in the LEO environment ${ }^{6}$, and darken with ultraviolet radiation exposure, a multi-layer metal oxide atomic oxygen (AO) and ultraviolet (UV) protective coating is deposited onto the silicone exterior. This coating was initially developed by the Boeing Company as part of an inter- 
nal development program for deposition on space concentrator arrays. This coated silicone configuration is being considered as an alternative to earlier ceriadoped microglass covered lens versions, ${ }^{1-3}$ due to advantages in manufacturing and handling.

The efficiency of a refractive photovoltaic concentrator system is directly related to the ability of the lens to focus incident radiation onto the active area of the solar cell. Therefore, the concentrator lens must maintain a high solar specular transmittance. The purpose of this investigation was to evaluate the LEO durability of coated silicone refractive concentrator materials. The primary LEO durability concerns with the coated silicone Fresnel lenses are the following: differences in the coefficient of thermal expansion (CTE) between the silicone substrate and the metal oxide protective coating, atomic oxygen interaction with exposed silicone at coating defect sites and potential silicone contamination issues, and overall protection afforded by the multi-layer coating. This evaluation was conducted with both ground-laboratory and in-space exposures of flat samples.

\section{Materials and Experimental Procedures}

\section{Materials}

The materials evaluated were flat $D C$ 93-500 silicone coated with a 11 layer $\left(\mathrm{SiO}_{2} / \mathrm{Al}_{2} \mathrm{O}_{3} / \mathrm{Ta}_{2} \mathrm{O}_{5}\right)$ thin film $A O$ and $U V$ resistant coating, and uncoated DC 93-500 silicone. Flat material was evaluated instead of refractive lenses, so that optical property measurements could be obtained.

\section{Optical Properties Characterization}

Total, diffuse and specular transmittances were obtained using a Perkin-Elmer $\lambda-9$ Spectrophotometer equipped with a $60 \mathrm{~mm}$ integrating sphere. Solar integrated values were obtained by measuring the spectral transmittance over the wavelengths of 250$2500 \mathrm{~nm}$, and convoluting the data into the air mass zero solar intensity curve over this range. Spectral transmittance uncertainty is $\pm 2 \%$.

\section{Surface and Mass Characterization}

Surface morphology changes as a function of atomic oxygen fluence were observed using optical microscopy and scanning electron microscopy (SEM). The optical microscope used was an Olympus SZH Stereo Microscope and micrographs were obtained at magnifications between 50-95 X. A Cambridge 200 Scanning Electron Microscope was used for high magnification imaging (up to $13 \mathrm{KX}$ ). Samples were coated with conductive Au films prior to SEM examination. X-ray Photoelectron Spectroscopy (XPS) analysis was conducted on pristine and groundlaboratory atomic oxygen exposed uncoated DC 93500. Both XPS surface analysis and XPS depth profiling was conducted. Dehydrated mass measurements of exposed samples were obtained using a Sartorius Balance, with an uncertainty of $\pm 50 \mu \mathrm{g}$.

\section{Ground-laboratory Atomic Oxygen}

A Structure Probe Inc. plasma asher was used to produce an atomic oxygen plasma environment. In addition to atomic oxygen the plasma contains a strong $130 \mathrm{~nm}$ line of UV radiation. ${ }^{7}$ Although the plasma asher does not provide identical atomic oxygen exposure conditions as in the LEO environment (due to differences in energy, flux, arrival direction, species, etc.), ashers are generally accepted as ground-laboratory systems for atomic oxygen durability evaluation. Effective fluence exposures were based on flux measurements obtained by ashing Kapton witness coupons in the asher prior to exposure of silicones, and calculating the flux based on the mass loss of the Kapton, and the erosion yield of Kapton in LEO $\left(3.0 \times 10^{-24} \mathrm{~cm}^{3} /\right.$ atom $){ }^{4}$ Samples were exposed to estimated effective fluences of up to $2.6 \times 10^{21}$ at$\mathrm{oms} / \mathrm{cm}^{2}$ based on a flux of $3 \times 10^{15}$ atoms $/ \mathrm{cm}^{2} \mathrm{sec}$.

One large and five small multi-layer metal oxide coated DC 93-500 samples were exposed to groundlaboratory atomic oxygen. The large sample (sample G7) was used for optical property measurements. Sample G7 was protected on the uncoated side with Al foil so that only degradation to the coated surface would occur and be analyzed. Sample G7 was iteratively exposed to an atomic oxygen effective fluence of $2.6 \times 10^{21}$ atoms $/ \mathrm{cm}^{2}$. Optical properties and dehydrated mass measurements were obtained every 48 hours. The five small samples (samples G2, G3, G4, G5, and G6) were placed into the asher with Sample G7. One small sample was taken out every 48 hours for destructive SEM evaluation, a sixth small sample (Sample G1) was kept unexposed. Each successive small sample for SEM evaluation had effective fluences ranging from 0 (sample G1) to 2.6 $\times 10^{21}$ atoms $/ \mathrm{cm}^{2}$ (sample G6) in increments of $5.2 \times$ $10^{20}$ atoms $/ \mathrm{cm}^{2}$.

\section{LEO Atomic Oxygen}

One uncoated flight sample (F1) and two multi-layer coated DC 93-500 flight samples (F2 and F3) were exposed to the LEO environment on the Environ- 
mental Oxygen Interaction with Materials (EOIM-III) Experiment. This experiment was exposed to LEO direct ram atomic oxygen on STS-46 (launched July $31,1992)$ and received an approximate fluence of 2.3 $X 10^{20}$ atoms $/ \mathrm{cm}^{2}$. Samples exposed in space received direct ram atomic oxygen exposure to the front side only and were set on polished stainless steel disk holders during flight.

\section{Results and Discussion}

\section{Surface Characterization Prior to Atomic Oxygen}

\section{Exposure}

The pristine multi-layer metal oxide coated DC 93500 samples evaluated contained coating cracks prior to any environmental exposure. These cracks may have been formed due to CTE mismatches between the coating and the DC $93-500$ or flexure during handling. Uncoated silicone samples did not contain any surface cracks prior to atomic oxygen exposure.

\section{Ground-Laboratory Atomic Oxygen}

The total transmittance of sample $\mathrm{G} 7$ was found to decrease from 0.834 to 0.796 , a decrease of 0.038 after a fluence of $1.0 \times 10^{21}$ atoms $/ \mathrm{cm}^{2}$, then remained stable around 0.793 until the final fluence of $2.6 \times 10^{21}$ atoms $/ \mathrm{cm}^{2}$ (see Figure 2). The specular transmittance was found to decrease continuously with exposure from 0.749 to 0.606 a decrease of 0.143 (also shown in Figure 2). Interference fringe patterns were observed in the spectral data for both the total and specular transmittance scans. Figure 3 shows an interference pattern in the total transmittance spectra between $350 \mathrm{~nm}-1200 \mathrm{~nm}$, which developed during atomic oxygen exposure. A single maximum $(\approx 550 \mathrm{~nm})$ and minimum $(\approx 460 \mathrm{~nm})$ of the interference pattern was first observed after a fluence of $1.0 \times 10^{21}$ atoms $/ \mathrm{cm}^{2}$ (96 hours of exposure). This interference pattern continued to develop throughout exposure, extending to larger wavelengths. The development of the interference pattern is likely to be the result of the deposition of a thin film on the surface of the sample. Silicone contamination of the Kapton witness coupon was observed during initial exposure (this is why the effective fluences were estimated based on previous flux calculations for that asher). Space flight exposures such as on the Long Duration Exposure Facility (LDEF) have provided evidence of spacecraft silicone contamination with exposure to a vacuum environment containing atomic oxygen and UV radiation. ${ }^{5,9}$ The interference pattern therefore appears to be the result of cross contamination from sili- cone at the coating crack sites which reacted with atomic oxygen (in a UV containing vacuum environment) resulting in a contaminant layer on the metal oxide coating. One of the LEO durability concerns with coated silicone advanced refractive concentrators is the possibility of cross contamination from the silicone. These results indicate that some initial total and specular transmittance loss appear to be due to silicone contamination.

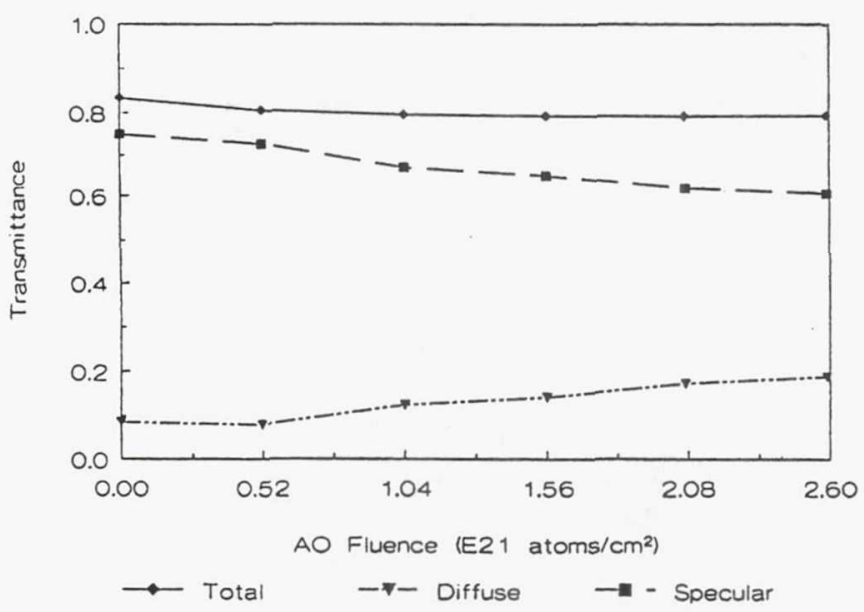

Figure 2. Transmittance changes as a function of atomic oxygen fluence for sample G7.

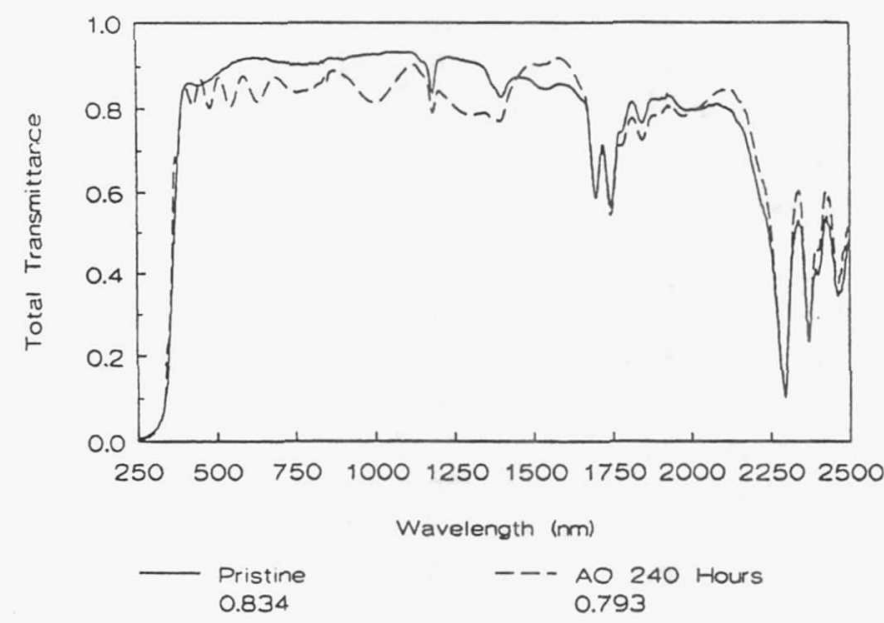

Figure 3. Total transmittance spectra of sample G7, before and after atomic oxygen exposure. A strong interference pattern is present in the spectra after an atomic oxygen fluence of 2.6 x $10^{21}$ atoms $/ \mathrm{cm}^{2}$ (240 hours). 
Optical microscopy examination of sample G7 revealed the development of additional coating cracks with continued atomic oxygen exposure (see Figure 4). The extent of additional coating cracking with plasma asher exposure was found to be very area specific. Figure 4 shows the area before and after atomic oxygen plasma exposure, with the most severe additional cracking observed. Note the non-uniform cracking density in the micrograph in Figure $4 \mathrm{C}$ after a fluence of $2.1 \times 10^{21}$ atoms $/ \mathrm{cm}^{2}$. Cracking associated with atomic oxygen plasma exposure was found to continue to progress with increased exposure time. This is likely to be due to the thermal cycling which was induced during the iterative ashing exposure. Refractive concentrators in space would also experience thermal cycling. The development of coating cracks will result in decreased specular transmittance.

To determine if the additional cracking of the multilayer coating during ground-laboratory exposure was due to atomic oxygen interactions or due to heating which can occur during plasma ashing (particularly with metals), additional experiments were conducted. Using adhesively attached temperature indicators, it was found that coated silicone samples were exposed to temperatures above $116^{\circ} \mathrm{C}$ in the plasma environment when they were completely protected with Al foil and to approximately $49^{\circ} \mathrm{C}$ when the samples were not in contact with metal (i.e. wrapped in organic material). Both of these temperatures were found to cause equivalent amounts of additional cracking of the protective coating. Sample G7 was protected on one side by $\mathrm{Al}$ foil during asher exposure so it's maximum temperature reached during ashing was probably at the high end of this temperature range. This cracking is attributed to the differences in CTE between the silicone and the metal oxide thin films $\left(\approx 10^{-4} /{ }^{\circ} \mathrm{C}\right.$ and $\approx 10^{-6} /{ }^{\circ} \mathrm{C}$, respectively). Figure 5 shows additional cracking of a coated silicone sample (G8) after being totally encased in Kapton during plasma ashing. Encasing the sample in Kapton resulted in sample heating, with no atomic oxygen exposure. This sample was exposed for 42 hours (equivalent to a fluence of $4.5 \times 10^{20}$ atoms $/ \mathrm{cm}^{2}$ ). When a sample was placed onto a small water-cooled holder in a heated asher, and maintained at $18^{\circ} \mathrm{C}$ for 48 hours the amount of cracking was significantly decreased. The few additional cracks were likely to be caused by handling. It was originally estimated that during LEO operation, the mini-dome Fresnel lenses would be exposed to temperatures up to $\approx 40.5^{\circ} \mathrm{C}$. A coated sample (sample G9), placed into a regular furnace maintained at $\simeq 40.5^{\circ} \mathrm{C}$, was found to show an in-

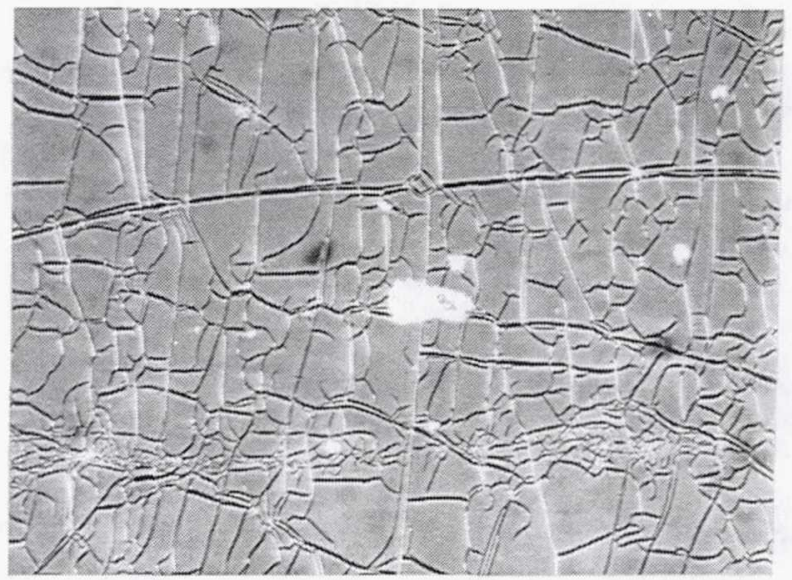

a.

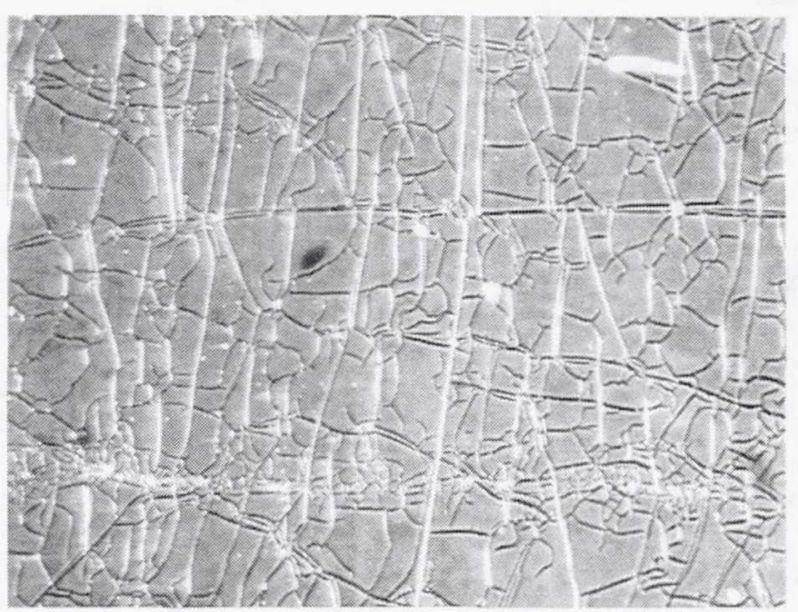

b.

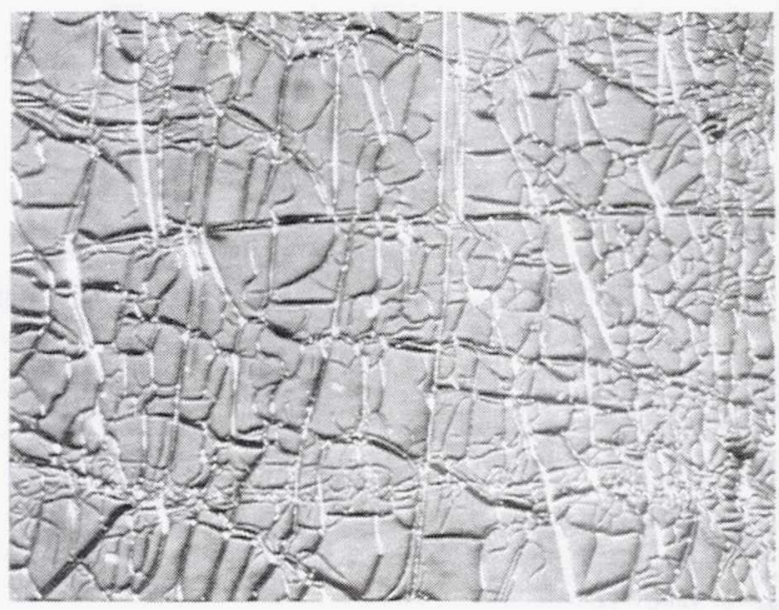

c.

Figure 4. Development of additional coating cracks on sample $\mathrm{G} 7$ with atomic oxygen plasma exposure: a. pristine, b. $\mathrm{F}=5.2 \times 10^{20}$ atoms $/ \mathrm{cm}^{2}$, and c. $\mathrm{F}=2.1 \times 10^{21}$ atoms $/ \mathrm{cm}^{2}$. 


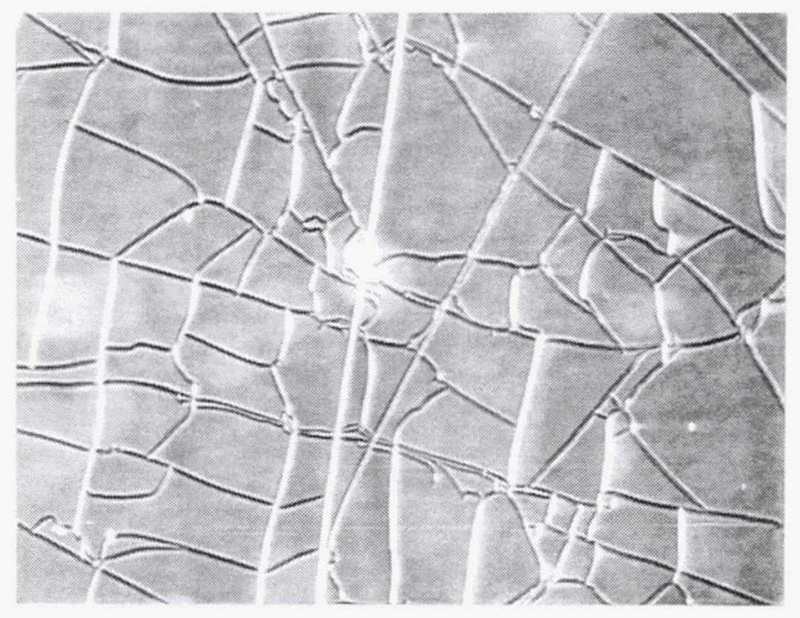

a.

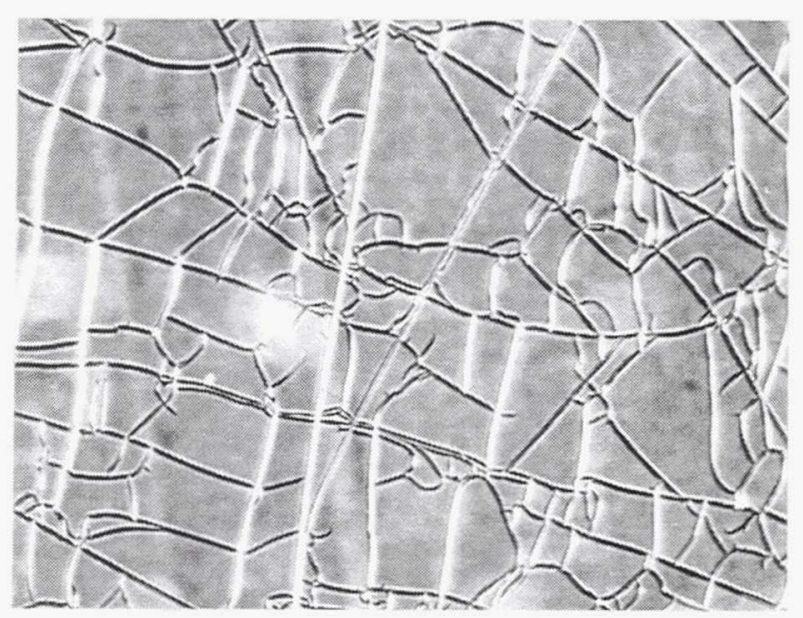

b.

Figure 5. Additional coating cracking of a coated silicone sample (G8) after being totally encased in Kapton during plasma ashing $\left(\approx 49^{\circ} \mathrm{C}\right)$ : a. prior to exposure, and b. after 42 hours of plasma exposure.

crease in coating cracks after a single 48 hour exposure (see Figure 6). This cracking intensity is almost as severe as the cracking observed with sample G7 after a fluence of $5.2 \times 10^{20}$ atoms $/ \mathrm{cm}^{2}$ (also 48 hours of exposure), as seen in Figure $4 b$. Therefore, heating during plasma asher exposure is causing the coated samples to crack further, but the originally estimated operating temperature in space $\left(40.5^{\circ} \mathrm{C}\right)$ was also found to cause coating cracking to a similar extent.

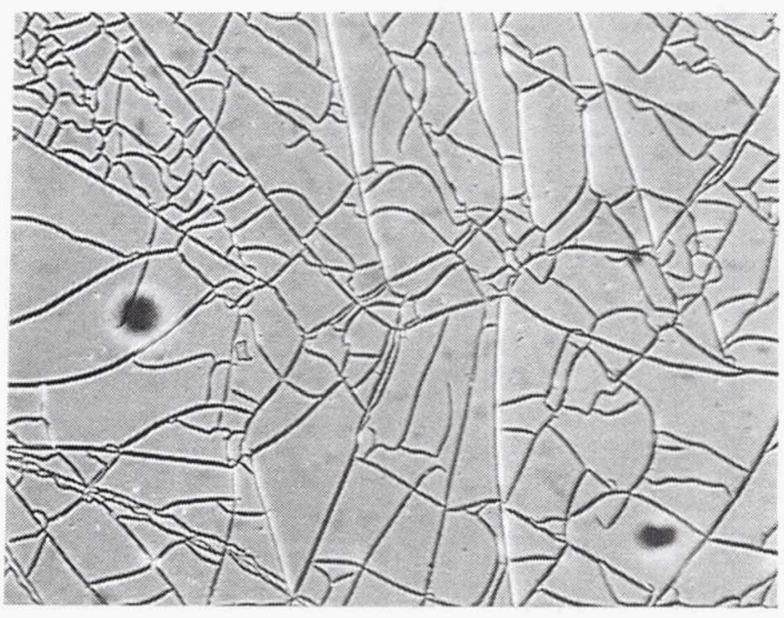

a.

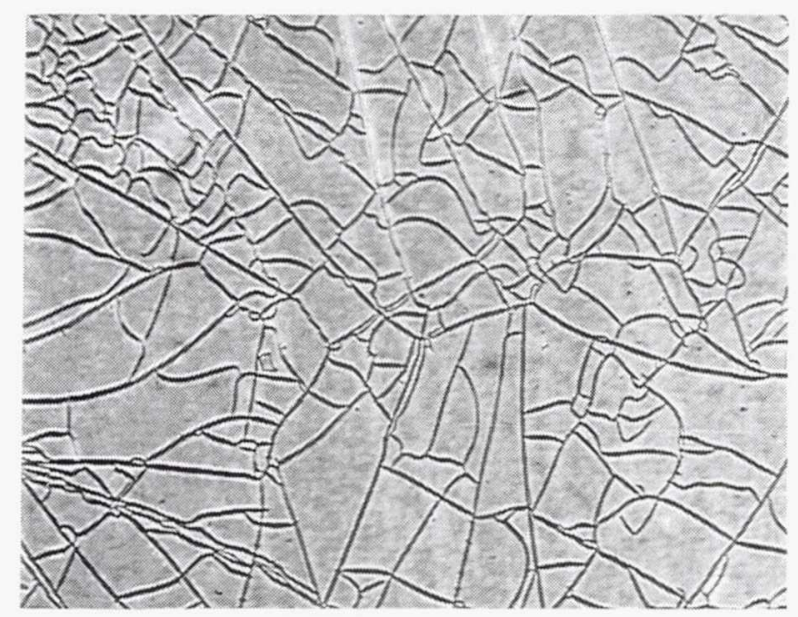

b.

Figure 6. Additional cracking of a coated silicone sample (G9) after being placed into a $40.5^{\circ} \mathrm{C}$ furnace for 48 hours: a. prior to expsure, and b. after exposure.

More tests were performed to evaluate the effect of additional cracking on the optical properties. An unexposed coated sample (sample B1) was characterized for transmittance and optical micrographs were taken. This sample was bent in half, then rolled along the bend line several times, and optical microscopy revealed extreme additional cracking of the coating had occurred, as can be seen in Figure 7. The post-bend optical measurements revealed a decrease in total and specular transmittance by only 0.005 and 0.023 , respectively. Therefore, any decreases in total and specular transmittance in excess of these values 
should not be attributed as an effect of protective coating cracking.

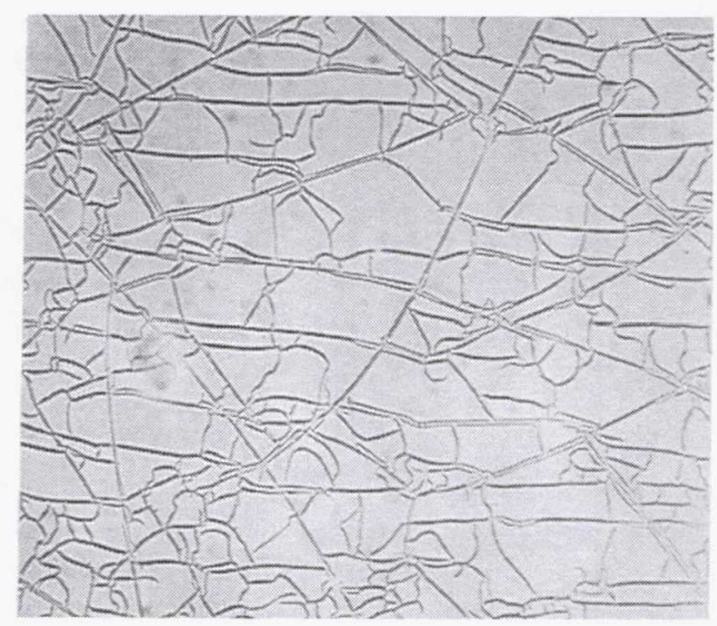

a.

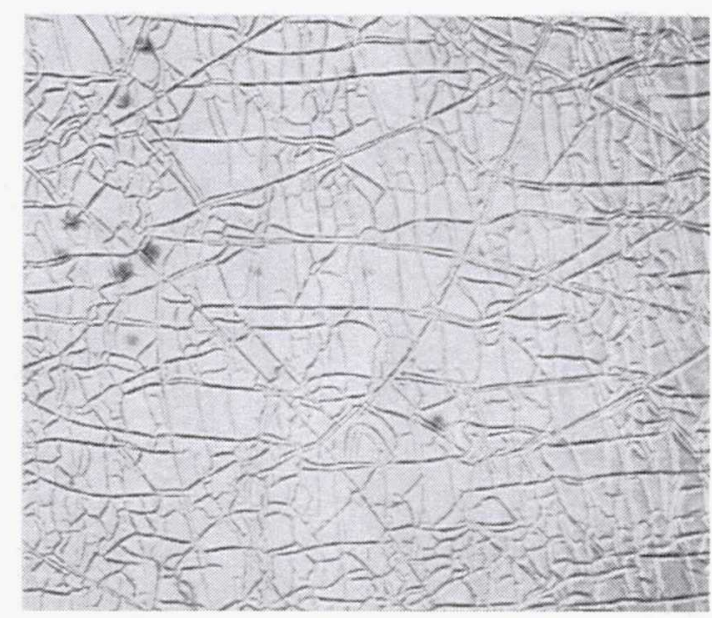

b.

Figure 7. Effect of severve bending (sample B1) on additional coating cracking: a. prior to bending, and $\mathrm{b}$. after bending.

A conservative adjustment to account for cracking effects on the optical property measurements of sample G7 after atomic oxygen exposure, would be to subtract 0.005 and 0.023 from the measured decreases in the total and specular transmittance, respectively. The resulting total and specular transmittance is then found to have decreased by at least 0.036 and 0.120 , respectively, after an atomic oxygen fluence of $2.6 \times 10^{21}$ atoms $/ \mathrm{cm}^{2}$ (this is equivalent to $\simeq 0.9$ years of sweeping space ram atomic oxygen exposure at space station altitudes). This shows that transmittance decreases are observed which are not associated with additional cracking. These decreases are attributed to film growth on the coated surface (as indicated by the presence of the interference pattern in the spectral data), and as previously mentioned is likely to be due to cross contamination from the exposed silicone at fresh crack sites.

In addition to the changes in transmittance of sample $\mathrm{G} 7$, there was a gain in mass of $0.46 \%$ with atomic oxygen exposure (see Figure 8 ). Scanning electron microscopy evaluation of samples G2-G6 showed the apparent formation of a smooth glassy layer on the exposed silicone in coating crack sites with atomic oxygen exposure. The mass gain and microscopy analysis provided evidence which suggested the formation of an $\mathrm{SiO}_{x}$ layer on the exposed silicone areas. To confirm this silicone to $\mathrm{SiO}_{x}$ conversion process XPS analysis was performed on four uncoated DC 93-500 samples. Two of these samples were pristine and two were exposed to atomic oxygen in a plasma asher with effective fluences of $6.11 \mathrm{x}$ $10^{19}$ atoms $/ \mathrm{cm}^{2}$ and $4.12 \times 10^{20}$ atoms $/ \mathrm{cm}^{2}$. The oxygen concentration on the surface of these samples showed a marked increase from $\approx 31$ atomic percent $(\mathrm{A} \%)$ to $\approx 59 \mathrm{~A} \%$, after an atomic oxygen fluence of $4.12 \times 10^{20}$ atom $/ \mathrm{cm}^{2}$, while the percent of silicon remained constant. The majority of oxygen concentration increase had occurred after an atomic oxygen fluence of $6.11 \times 10^{19}$ atoms $/ \mathrm{cm}^{2}(\approx 57 \mathrm{~A} \%$ ), indicating that the rate of oxygen increase slowed with exposure time (see Figure 9). Further analysis of the above samples revealed that the percent of $\mathrm{SiO}_{\mathrm{x}}$ on the surface of the samples increased from $\approx 26 \%$ to $\approx 77 \%$ after a fluence of $4.12 \times 10^{20}$ atoms $/ \mathrm{cm}^{2}$. The majority of the $\mathrm{SiO}_{3}$ conversion occurred within a fluence of $6.11 \times 10^{19}$ atoms $/ \mathrm{cm}^{2}(\approx 72 \%)$ (see Figure 10). The decrease in the rate of this conversion process with longer fluences is attributed to less surface area of the silicone being exposed to the atomic oxygen as the silicate layer forms. Depth profiling of the above samples showed that the $\mathrm{SiO}_{\mathrm{x}}$ layer increased in depth as the atomic oxygen effective fluence increased. At $6.11 \times 10^{19}$ atoms $/ \mathrm{cm}^{2}$ the depth of the $\mathrm{SiO}_{\mathrm{X}}$ layer was measured to be $\approx 1000 \AA$ and at an effective fluence of $4.12 \times 10^{20}$ atoms $/ \mathrm{cm}^{2}$ the depth of the $\mathrm{SiO}_{\mathrm{x}}$ layer was measured to be greater than $2000 \AA$. The continued conversion of silicone to $\mathrm{SiO}_{\mathrm{x}}$ after an initial surface $\mathrm{SiO}_{x}$ layer has formed, is speculated to be due to the ability of atomic oxygen to diffuse through the $\mathrm{SiO}_{x}$ layer (due to incomplete conversion of the silicone to silica) to react with underlying silicone. 


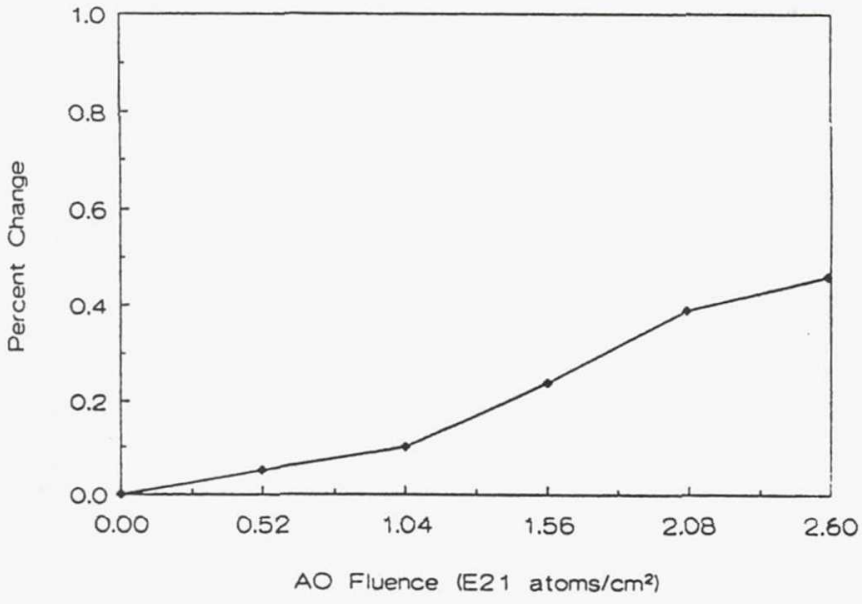

Figure 8. Gain in mass of Sample G7 with atomic oxygen plasma exposure.

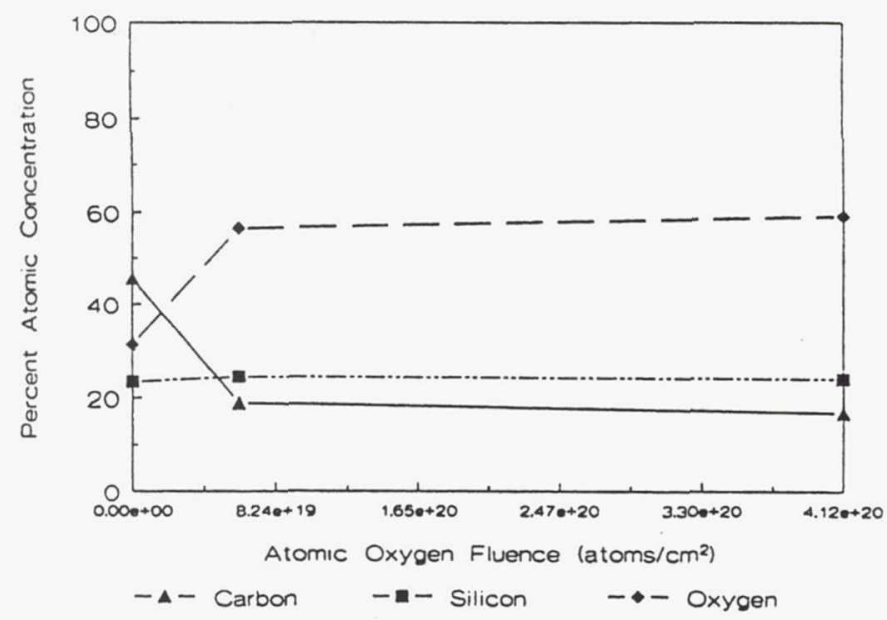

Figure 9. Surface atomic concentrations of $\mathrm{O}, \mathrm{C}$, and $\mathrm{Si}$ for uncoated DC 93-500 silicone as a function of atomic oxygen fluence.

When the surface of silicone converts to $\mathrm{SiO}_{x}$ with atomic oxygen exposure, it typically looses organic side groups such as methyl groups, shrinks and causes mud tile like cracks (note the loss of carbon in Figure 9). SEM evaluation of samples G2-G6 provided images where silicone in the coating cracks had converted to $\mathrm{SiO}_{x}$, cracked, formed $\mathrm{SiO}_{x}$ in that crack and cracked again. This type of $\mathrm{SiO}_{x}$ conversion cracking propagation is shown in Figure 11 . Figure 11a shows a freshly opened crack with a stretched appearance (vertical), and an older crack which has a smoothed out glassy appearance (horizontal). Figure $11 \mathrm{~b}$ shows cracking of the converted $\mathrm{SiO}_{x}$ layer inside a coating crack. "Bulging" of the coated areas be-

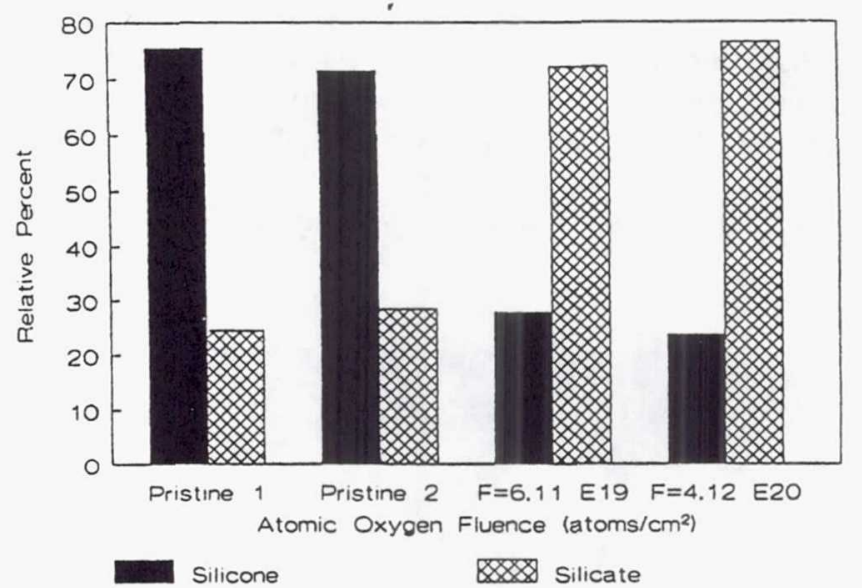

Figure 10. Relative percentages of silicone and $\mathrm{SiO}_{\mathrm{x}}$ on the surface of uncoated DC 93-500 silicone as a function of atomic oxygen fluence.

tween cracks (islands) was also observed with SEM. Typically this bulging, as observed at room temperature, was found to increase with increased atomic oxygen exposure. This effect is observable as extra shadowing in the higher fluence optical micrographs, such as the one in Figure 4c. In some isolated areas the bulging islands actually appear to have partially delaminated from the silicone substrate such that the edges are free and lifted up, as can be seen in Figure 12. These islands appear to be adhered to the silicone. Only a few islands were actually found to have flaked off. SEM evaluation also provided evidence that the multi-layer coating remained protective and did not appear eroded by atomic oxygen in the areas where it was not cracked.

\section{LEO Atomic Oxygen}

Sample F2, the coated DC 93-500 sample, exposed to directed ram space atomic oxygen experienced essentially no change in the integrated total transmittance and a 0.031 decrease in the integrated specular transmittance (sample F3 is still being characterized). No decrease in total transmittance, and a slight decrease in specular transmittance is consistent with the changes observed in the bend test sample. However, optical post-flight macrographs of sample F2 show only a slight amount of additional cracking (see Figure 13), not enough to account for the specular transmittance change based on results from the bend test sample (the defect in the center of the macrograph was purposely put there prior to flight). The additional decrease in specular transmittance for the LEO exposed sample is not currently 
understood. SEM analysis of sample F2 has not yet been performed. It is possible that such analysis will give insight into this decrease in specular transmittance. It has been observed that the EOIM III mission fluence was high enough to cause the uncoated silicone sample to craze (see Figure 14).

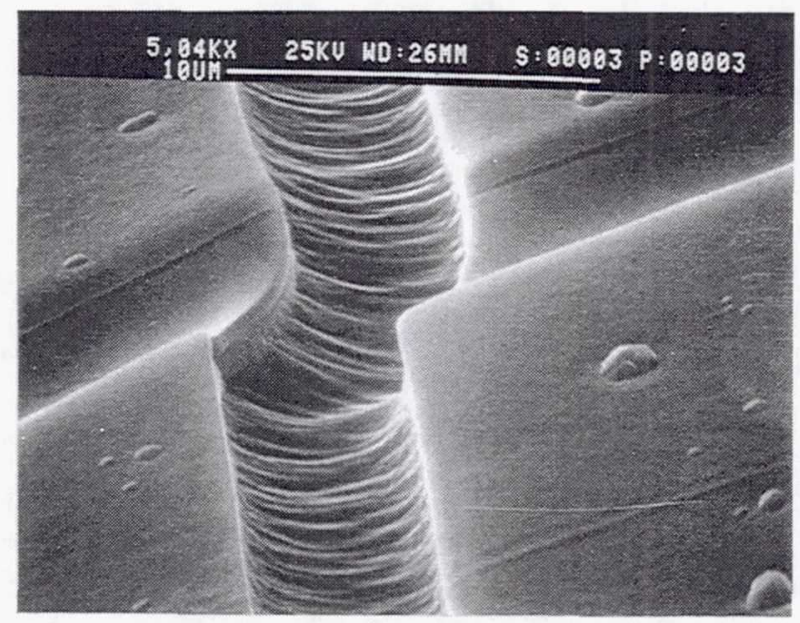

a.

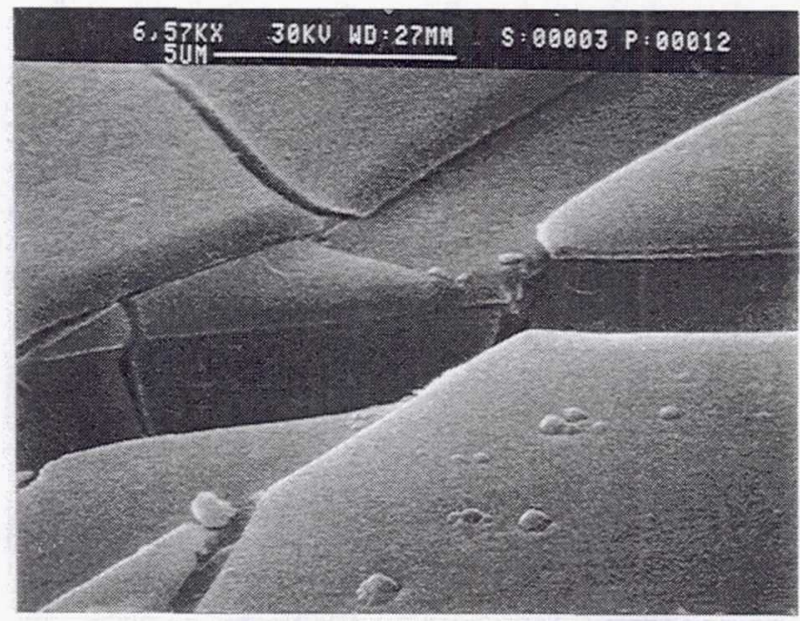

b.

Figure 11. SEM micrographs showing the development of coating cracks after an atomic oxygen fluence of $2.6 \times 10^{21}$ atoms $/ \mathrm{cm}^{2}$ : a. freshly opened crack (stretched appearance), and an older $\mathrm{SiO}_{\mathrm{x}}$ converted crack (smooth glassy appearance), and $b$. cracking of $\mathrm{SiO}_{x}$ converted film inside a protective coating crack.

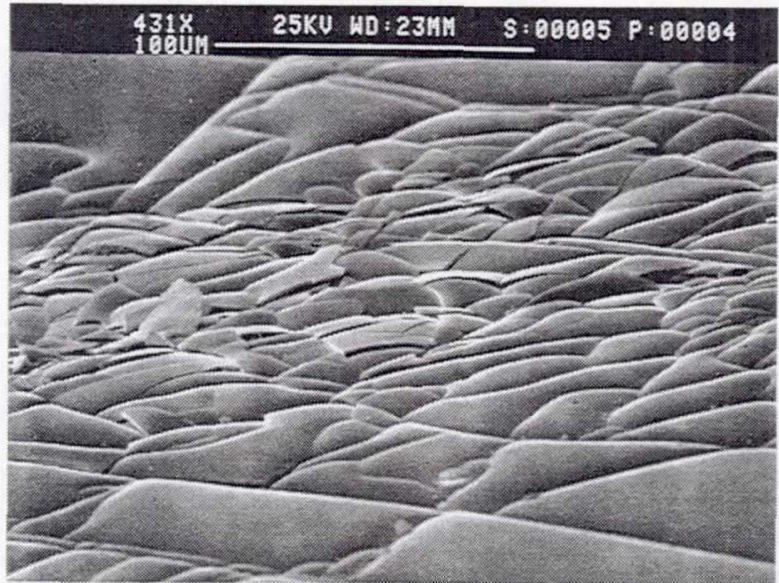

Figure 12. Isolated area of partically delaminated "bulged" coating islands.

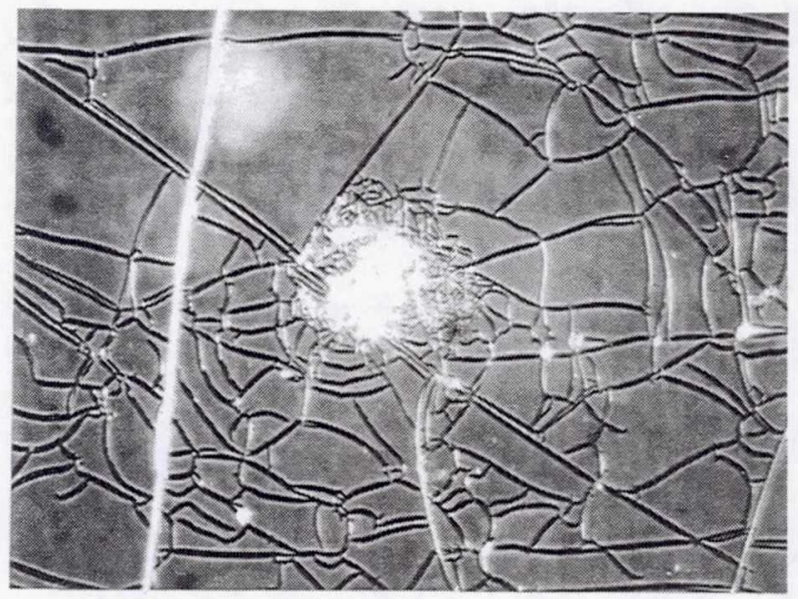

a.

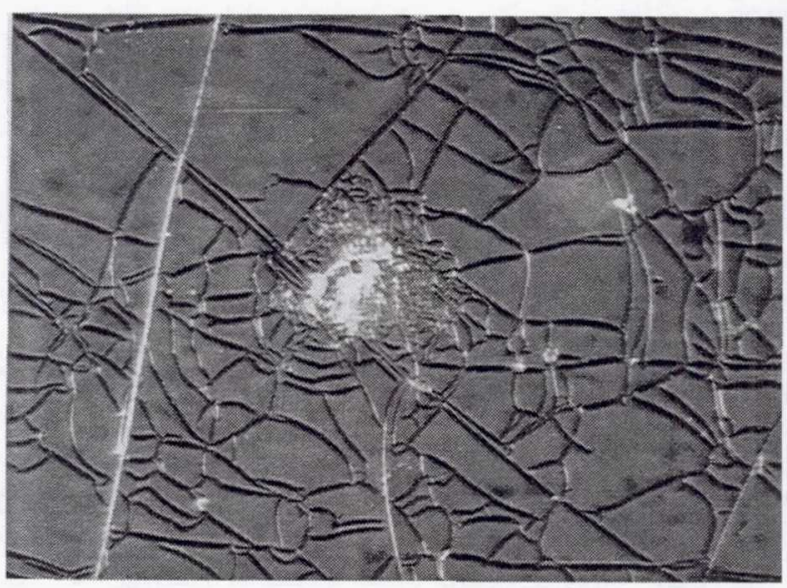

b.

Figure 13. Coated DC 93-500 silicone exposed to LEO on STS-46: a. pre-flight, and b. post-flight $\left(\mathrm{F}=2.3 \times 10^{20}\right.$ atoms $\left./ \mathrm{cm}^{2}\right)$. 


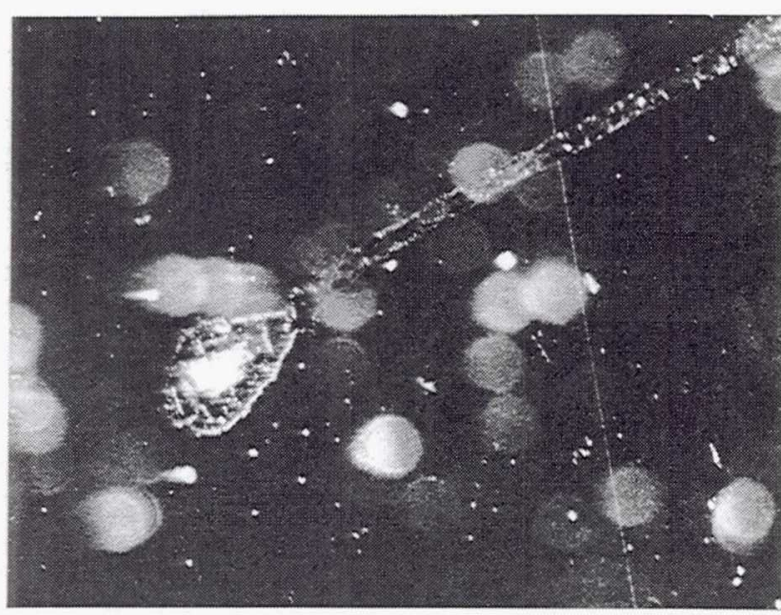

a.

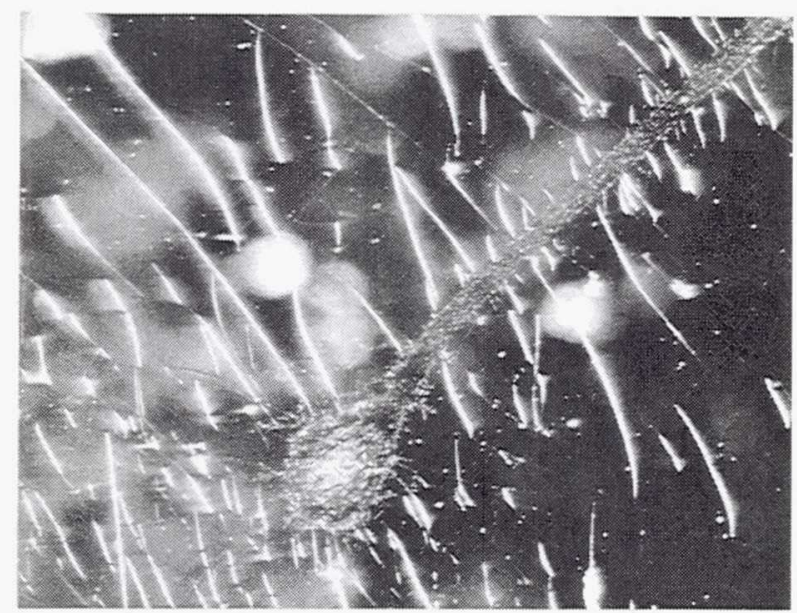

b.

Figure 14. Uncoated DC 93-500 exposed to LEO on STS-46: a. pre-flight (no cracks), and b. postflight $\left(\mathrm{SiO}_{\mathrm{x}}\right.$ conversion cracks).

Small changes were noted in both the total and specular transmittance spectra of sample F2. These changes are not consistent with the changes that occurred in total or specular transmittance spectra of the bend test sample. The bend test sample shows virtually no change in it's total transmittance spectra before and after bending. The total transmittance spectra of sample F2, however, shows a slight decrease between approximately 375 and $500 \mathrm{~nm}$, and a slight increase between approximately 625 and 2125 $\mathrm{nm}$ (see figure 15). The specular transmittance spectra of the bend test sample showed a fairly uniform drop across the range of 250-2125 $\mathrm{nm}$. In contrast, the specular transmittance spectra of sample
F2 showed a larger decrease in the lower wavelengths of this range $(\simeq 350-700 \mathrm{~nm})$ and a smaller decrease in the higher wavelengths of this range ( $\simeq 1300-2125 \mathrm{~nm}$ ). These spectra differences suggest that there is an additional mechanism effecting the optical properties of the atomic oxygen exposed samples besides the additional cracking. Because these changes do appear to occur in the spectra of sample G7 at the lowest fluence interval ( $F=5.2 \times 10^{20}$ atoms $/ \mathrm{cm}^{2}$ ), it is possible that a contaminant film had started to develop on the flight sample. Further tests need to be performed to verify this. As previously mentioned, cross contamination of silicone products was widely observed all over the Long Duration Exposure Facility. ${ }^{9}$ The transmittance data for sample F2 did not show an interference pattern, but the interference pattern was also not present in the spectra of sample G7 until a fluence of $1.0 \times 10^{21}$ atoms $/ \mathrm{cm}^{2}$. The EOIM III fluence, $2.3 \times 10^{20}$ atoms $/ \mathrm{cm}^{2}$ would be equivalent to approximately 21 hours of ground-laboratory exposure.

\section{Conclusions}

Multi-layer metal oxide coated silicone refractive concentrator material was exposed to ground-laboratory and in-space ultraviolet containing atomic oxygen environments. Ground laboratory exposures indicated a slight drop in total transmittance initially $(0.834$ to 0.796 ), with total transmittance becoming stable with further exposure at 0.793 (decrease of 0.041). The specular transmittance was found to decrease continuously with exposure $(0.749$ to 0.606 , a decrease of 0.143). Coating cracks present on the pristine sample, were found to continue to develop with environmental exposure. Additional coating cracks were found to be caused by heating to temperatures as low as $40.5^{\circ} \mathrm{C}$. Bend test results show that decreases in total and specular transmittance up to only 0.005 and 0.023 , respectively, could be attributed to additional cracking. Interference fringe patterns in the spectral data indicated the development of a contamination layer during exposure. The source of contamination is most likely due to the reaction of atomic oxygen with exposed silicone at coating crack sites, in a UV containing environment. Mass measurements, SEM analysis and XPS data support the formation of surface $\mathrm{SiO}_{x}$ at exposed silicone areas in coating crack sites. Evidence of silicone to $\mathrm{SiO}_{x}$ conversion in coating cracks, in addition to the knowledge of results such as those on LDEF, indicates that a byproduct of silicone contamination is likely to have occ- 
urred resulting in a contaminant film which contributed to total and specular transmittance loss.

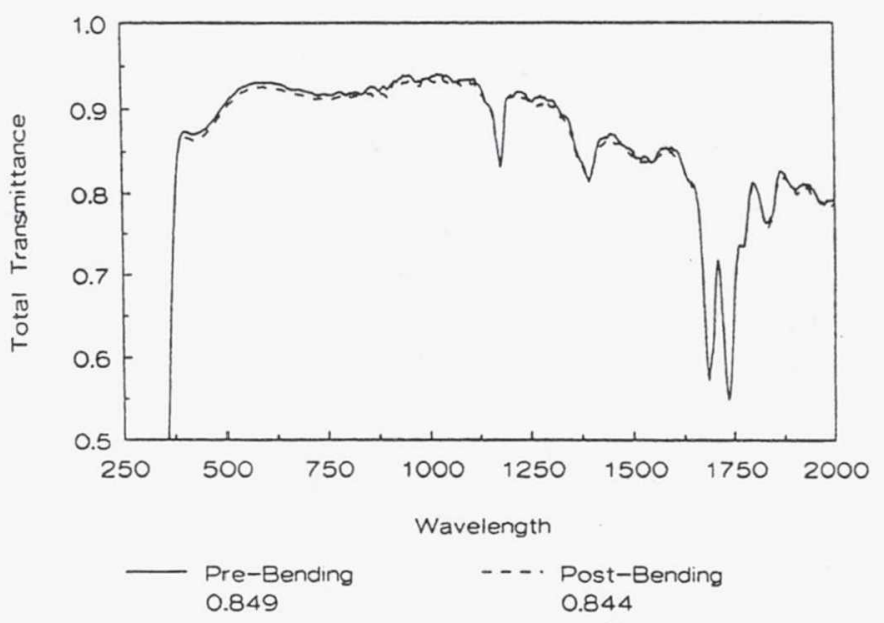

a.

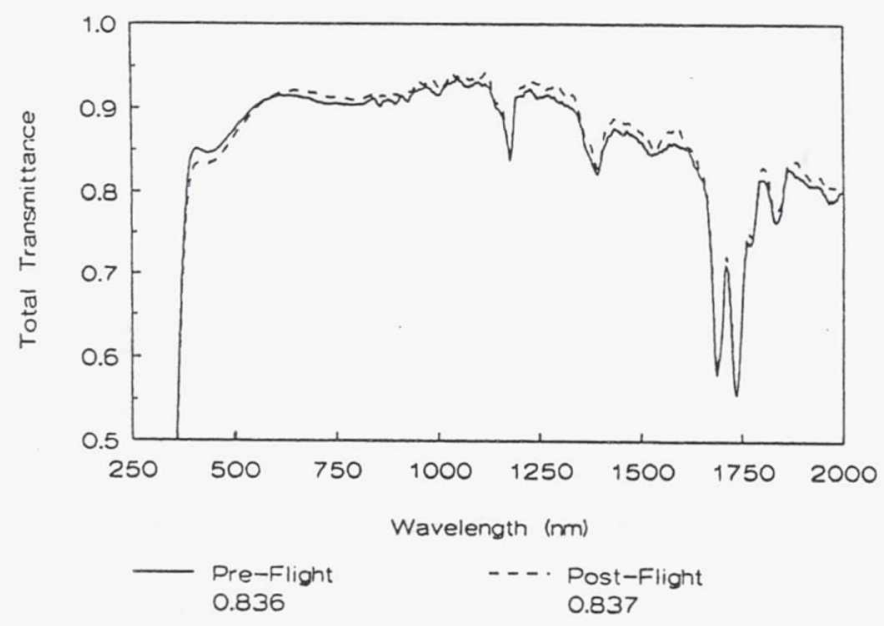

b.

Figure 15. Comparison of total transmittance spectral changes of coated DC 93-500 exposed to severe bending and to LEO atomic oxygen: a. before and after severe bending, and b. preand post-flight.

Preliminary analysis of coated silicone flight samples exposed to LEO atomic oxygen on EOIM III seem to indicate that similar cracking and contamination problems occurred in space as they did during ground testing, but further analysis is needed to verify these results

Longer term space flight exposures of refractive concentrator materials, and ground-laboratory and inspace exposure of actual refractive concentrators are needed to verify the long term effects of atomic oxygen, ultraviolet radiation and thermal cycling on the optical properties of refractive concentrators. Two passive mini-dome Fresnel lenses will be flown in early 1994 on STS-60, and an active experiment, the Photovoltaic Array Space Power Plus Diagnostics Flight Experiment ${ }^{1}$, will be flown 1994 on the Advanced Photovoltaic and Electronics Experiment (APEX) scheduled for a Pegasus launch in the spring of 1994. Both of these space flight experiments have multi-layer metal oxide coated silicone concentrators.

Although modified techniques have been found to significantly decrease the number of metal oxide coating cracks formed during coating deposition, this study provides evidence that coating cracks will develop at temperatures as low as $40.5^{\circ} \mathrm{C}$. If the currently found cracking and contamination results are confirmed with the space flight experiments and further analyses, the multi-layer coated silicone does not appear to be promising for LEO applications when operating temperatures reach $40.5^{\circ} \mathrm{C}$. However, more recent studies have shown that the operating temperature range of the mini-dome Fresnel lenses in LEO is more likely to be between $-29^{\circ} \mathrm{C}$ and $10^{\circ} \mathrm{C}$ and is very dependent on the concentrator array design. In LEO application in which the operating temperatures are between $-29^{\circ} \mathrm{C}$ to $10^{\circ} \mathrm{C}$ the multi-layer coating may be acceptable, however, low temperature thermal exposures and thermal cycling have not been performed to evaluate the effects of these temperatures on the integrity of the coating. Further testing should be done to study the effects of these conditions on the coated silicone lens material. Also testing should be done to evaluate the effects that stresses place on the coating due to thermal gradients in the refractive concentrators as a potential source of coating cracks.

Due to the observed sensitivity of CTE mismatches between the metal oxide protective coating and silicone substrate, and potential silicone contamination, alternate materials configurations should be considered for LEO applications. The ceria-doped microglass covered silicone should continue to be evaluated and alternate substrates with lower CTE's that do not produce contaminant by-products in an $A O$ environment should also be considered and evaluated. In orbital environments with low $A O$ populations, such as GEO or polar orbits, contaminations from the silicone substrate will not be an issue and the multilayer coated silicone configuration may be attractive if thermal stresses on the concentrators can be minimized. 


\section{References}

1 M. F. Piszczor, D. J. Brinker, D. J. Flood, J. E. Avery, L. M. Fraas, E. S. Fairbanks, J. W. Yerkes \& M. J. O'Neill, "A High-Performance Photovoltaic Concentrator Array: The Mini-Dome Fresnel Lens Concentrator with 30\% Efficient GaAs/GaSb Tandem Cells," Proceedings of the 22nd IEEE Photovoltaic Specialist Conference, Las Vegas, NV, Oct. 1991, pp. 1485-1490.

2 M.F. Piszczor, C. K. Swartz, \& M. J. O'Neill, "Component and Prototype Panel Testing of the Mini-Dome Fresnel Lens Photovoltaic Concentrator Array," Proceedings of the 25th Intersociety Energy Conversion Engineering Conference, 1990 , pp. 593-603.

3 M. F. Piszczor, M. J. O'Neill \& L. M. Fraas, "The Mini-Dome Fresnel Lens Photovoltaic Concentrator Array: Current Program Status," Proceedings of the 26th IECEC Conference, Boston, MA, Aug. 4-9, 1991, Vol. II, pp. 298-303.

4 M. F. Piszczor Jr., M. J. O’Neill \& L. M. Fraas, "A Novel Space Photovoltaic Module Using a Linear Fresnel Lens and a Line-Focus Tandem Cell Receiver" Proceedings of the 23rd IEEE Photovoltaic Specialist Conference, Louisville, KY, May 1014, 1993, pp. 1386-1392.

5 B. A. Banks, J. A. Dever, L. Gebauer \& C. M. Hill, " Atomic Oxygen Interactions with FEP Teflon and Silicones on LDEF", Proceedings of the LDEF First Post-Retrieval Symposium, Kissimmee, FL, June 2-8, 1991, NASA CP 3134, Part 2, pp. 801815.

6 U.S. Standard Atmosphere 1976 (U.S. Government Printing Office, Washington, D.C., 1976), p. 30.

7 S. L. Koontz, K. Albyn and L. J. Leger, "Atomic Oxygen Testing with Thermal Atom Systems: A Critical Evaluation", J. Spacecraft \& Rockets, Vol. 28, No. 3, May-June, 1991, pp. 315-323.

8 L. J. Leger \& J. T. Visentine, "A Consideration of Atomic Oxygen Interactions with the Space Station," J. Spacecraft \& Rockets, Vol. 23, No. 5, Sept.-Oct., 1986, pp. 505-511.
9 E. R. Crutcher \& K. J. Warner, "Molecular Films Associated with LDEF", Proceedings of the LDEF First Post-Retrieval Symposium, Kissimmee, FL, June 2-8, 1991, NASA CP 3134, Part 1, pp. 155177.

\section{Acknowledgements}

The authors would like to thank Michael F. Piszczor of NASA Lewis for his support on this program, The Boeing Defense and Space Group for supplying the materials for both ground-laboratory and space flight exposure, Judith A. Terlep of Ohio Aerospace Institue for pre-flight microscopy of the flight samples, and Jeff Shallenberger at Evans East for conducting the extensive XPS analyses. 
Public reporting burden for this collection of information is estimated to average 1 hour per response, including the time for reviewing instructions, searching existing data sources, gathering and maintaining the data needed, and completing and reviewing the collection of information. Send comments regarding this burden estimate or any other aspect of this collection of information, including suggestions for reducing this burden, to Washington Headquarters Services, Directorate for Information Operations and Reports, 1215 Jefferson Davis Highway, Suite 1204, Arlington, VA 22202-4302, and to the Office of Management and Budget, Paperwork Reduction Project (0704-0188), Washington, DC 20503.
1. AGENCY USE ONLY (Leave blank)
2. REPORT DATE
April 1994
3. REPORT TYPE AND DATES COVERED
Technical Memorandum

\section{TITLE AND SUBTITLE}

Low Earth Orbit Durability Evaluation of Protected Silicone for

Advanced Refractive Photovoltaic Concentrator Arrays

6. $A U T H O R(S)$

WU-506-41-11

Kim K. de Groh and Timothy A. McCollum

7. PERFORMING ORGANIZATION NAME(S) AND ADDRESS(ES)

8. PERFORMING ORGANIZATION REPORT NUMBER

National Aeronautics and Space Administration

Lewis Research Center

E-8687

Cleveland, Ohio 44135-3191

9. SPONSORING/MONITORING AGENCY NAME(S) AND ADDRESS(ES)

10. SPONSORING/MONITORING AGENCY REPORT NUMBER

National Aeronautics and Space Administration

Washington, D.C. 20546-0001

NASA TM-106543

AIAA-94-0374

\section{SUPPLEMENTARY NOTES}

Prepared for the AIAA 32nd Aerospace Sciences Meeting and Exhibit sponsored by the American Institute of Aeronautics and Astronautics, Reno, Nevada, January 10-13, 1994. Kim K. de Groh, NASA Lewis Research Center; and Timothy A. McCollum, Cleveland State University, Cleveland, Ohio 44115. Responsible person, Kim K. de Groh, organization code 5480, (216) $433-2297$.

12a. DISTRIBUTION/AVAILABILITY STATEMENT 12b. DISTRIBUTION CODE

Unclassified - Unlimited

Subject Category 20

\section{ABSTRACT (Maximum 200 words)}

The need for efficient, cost effective sources of electrical power in space has led to the development of photovoltaic power systems which make use of novel refraction solar concentrators. These concentrators have been conceived in both point-focus and linear-focus designs. Current concentrator lenses are fabricated from flexible silicones with Fresnel facets along the inside surface. To insure the efficient operation of these power systems, the concentrator lenses must be durable and the silicone material must remain specularly transmitting over a reasonable lifetime in low Earth orbit (LEO) and other space environments. Because of the vulnerability of silicones to atomic oxygen and ultraviolet radiation in LEO these lenses have been coated with a multi-layer metal oxide protective coating. The objectivity of this research was to evaluate the LEO durability of the multi-layer coated silicone for advanced refractive photovoltaic concentrator arrays with respect to optical properties and microstructure. Flat metal oxide coated silicone samples were exposed to groundlaboratory and in-space atomic oxygen for durability evaluation.

\section{SUBJECT TERMS}

15. NUMBER OF PAGES

Atomic oxygen; Fresnel lens; Ultraviolet radiation; Protective coating;

DC 93-500 silicone; Total transmittance; Specular transmittance
13

16. PRICE CODE

$\mathrm{AO} 3$

20. LIMITATION OF ABSTRACT
17. SECURITY CLASSIFICATION OF REPORT Unclassified
18. SECURITY CLASSIFICATION OF THIS PAGE

Unclassified
19. SECURITY CLASSIFICATION OF ABSTRACT Unclassified 